\title{
Predictors and outcomes of high-flow nasal cannula failure following extubation: A multicentre observational study
}

Amit $\underline{K a n s a l}^{1}{ }_{F C I C M}$, Shekhar Dhanvijay ${ }^{1}{ }_{F C I C M}$, Andrew $\underline{\mathrm{Li}}^{2,3}{ }_{M R C P}$, Jason Phua ${ }^{2,3,4}{ }_{M R C P}$, Matthew Edward $\underline{\text { Cove }}^{2,3}{ }_{M B C h B}$,

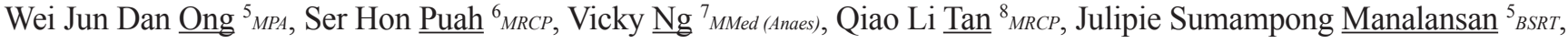
Michael Sharey Nocon Zamora ${ }_{B S R T}$, Michael Camba Vidanes ${ }^{5}{ }_{B S R T}$, Juliet Tolentino Sahagun ${ }^{9}{ }_{B S R T}$, Juvel Taculod ${ }^{9}$ MHA, Addy Yong-Hui Tan ${ }^{10}$ MMed (Anaes), Chee Kiang Tay ${ }^{8}{ }_{M R C P}$, Yew Woon Chia ${ }^{11}{ }_{F R C P}$, Duu Wen Sewa ${ }^{8}$ MRCP, Meiying Chew ${ }^{2,3}{ }_{\text {MRCP }}$, Sennen JW Lew ${ }^{6}{ }_{\text {MRCP }}$, Shirley $\underline{\text { Goh }}{ }^{7}{ }_{\text {MMed (Anaes) }}$, Jonathan Jit-Ern $\underline{\text { Tan }}^{7}{ }_{\text {FANZCA, }}$ Kollengode Ramanathan ${ }^{3,12}$ FCICM, Amartya Mukhopadhyay ${ }^{2,3,13_{F R C P}}$, Kay Choong $\underline{\text { See }}^{2,3 F C P P}$, on behalf of Society of Intensive Care Medicine (Singapore) - National Investigators for Clinical Epidemiology and Research (SICM-NICER)

\begin{abstract}
Introduction: Despite adhering to criteria for extubation, up to $20 \%$ of intensive care patients require re-intubation, even with use of post-extubation high-flow nasal cannula (HFNC). This study aims to identify independent predictors and outcomes of extubation failure in patients who failed postextubation HFNC.

Methods: We conducted a multicentre observational study involving 9 adult intensive care units (ICUs) across 5 public hospitals in Singapore. We included patients extubated to HFNC following spontaneous breathing trials. We compared patients who were successfully weaned off HFNC with those who failed HFNC (defined as re-intubation $\leq 7$ days following extubation). Generalised additive logistic regression analysis was used to identify independent risk factors for failed HFNC.

Results: Among 244 patients (mean age: 63.92 \pm 15.51 years, 65.2\% male, median APACHE II score 23.55 7.35), 41 (16.8\%) failed HFNC; hypoxia, hypercapnia and excessive secretions were primary reasons. Stroke was an independent predictor of HFNC failure (odds ratio 2.48, 95\% confidence interval 1.83-3.37). Failed HFNC, as compared to successful HFNC, was associated with increased median ICU length of stay (14 versus 7 days, $P<0.001)$, ICU mortality $(14.6 \%$ versus $2.0 \%, P<0.001)$ and hospital mortality $(29.3 \%$ versus $12.3 \%, P=0.006)$.

Conclusion: Post-extubation HFNC failure, especially in patients with stroke as a comorbidity, remains a clinical challenge and predicts poorer clinical outcomes. Our observational study highlights the need for future prospective trials to better identify patients at high risk of post-extubation HFNC failure.
\end{abstract}

Ann Acad Med Singap 2021;50:467-73

Keywords: Adult, airway extubation, high-flow nasal cannula, mechanical ventilation, respiratory failure

\footnotetext{
${ }^{1}$ Department of Intensive Care Medicine, Ng Teng Fong General Hospital, Singapore

${ }^{2}$ Division of Respiratory and Critical Care Medicine, Department of Medicine, National University Hospital, Singapore

${ }^{3}$ Yong Loo Lin School of Medicine, National University of Singapore, Singapore

${ }^{4}$ Fast and Chronic Programmes, Alexandra Hospital, Singapore

${ }^{5}$ Department of Respiratory Therapy, Ng Teng Fong General Hospital, Singapore

${ }^{6}$ Department of Respiratory and Critical Care Medicine, Tan Tock Seng Hospital, Singapore

${ }^{7}$ Department of Anaesthesiology, Intensive Care and Pain Medicine, Tan Tock Seng Hospital, Singapore

${ }^{8}$ Department of Respiratory Medicine and Critical Care Medicine, Singapore General Hospital, Singapore

${ }^{9}$ Division of Critical Care, National University Hospital, Singapore

${ }^{10}$ Department of Anaesthesia, National University Hospital, Singapore

${ }^{11}$ Department of Cardiology, Tan Tock Seng Hospital, Singapore

${ }^{12}$ Department of Cardiac Thoracic and Vascular Surgery, National University Heart Centre, Singapore

${ }^{13}$ Medical Affairs, Alexandra Hospital, Singapore

Correspondence: Dr Amit Kansal, Department of Intensive Care Medicine, Ng Teng Fong General Hospital, 1 Jurong East Street 21, Singapore 609606.

Email: Kansal_Amit@nuhs.edu.sg
} 


\section{CLINICAL IMPACT}

\section{What is New}

- One in 6 patients need re-intubation when high-flow nasal cannula (HFNC) is used to facilitate extubation and such patients have poorer clinical outcomes.

- Our study identified stroke as a comorbidity and the only independent predictor of HFNC failure.

\section{Clinical Implications}

- Post-extubation HFNC failure remains a clinical challenge and is associated with poorer clinical outcomes.

- Patients with a history of stroke are at high risk of post-extubation HFNC failure, suggesting these patients need closer monitoring.

\section{INTRODUCTION}

Mechanical ventilation (MV) is associated with multiple complications, including ventilator-associated pneumonia, pulmonary barotrauma, myopathy and ventilator-induced diaphragm dysfunction, haemodynamic alterations, decreased splanchnic perfusion, gastrointestinal stress ulceration and disordered sleep. ${ }^{1}$ These complications could be reduced by limiting the duration of MV and early extubation. However, among patients undergoing planned extubation, 10 to $20 \%$ patients will require re-intubation..$^{2-4}$ In turn, extubation failure has been associated with longer intensive care unit (ICU) and hospital length of stay (LOS), and increased hospital mortality. ${ }^{4-6}$

High-flow nasal cannula (HFNC) has been used to support patients after extubation to reduce the risk of re-intubation. ${ }^{7-11}$ HFNC can reduce the risk of reintubation via multiple mechanisms including continuous alveolar recruitment, reduction of airway collapse with improvement of the ventilation-perfusion mismatch; ${ }^{12,13}$ improved inspiratory flow dynamics, ${ }^{14,15}$ preserved mucosal function due to heated humidification which may result in better secretion clearance; ${ }^{16}$ and potential dead space washout effect facilitating carbon dioxide clearance. ${ }^{17}$

The patients most likely to benefit from HFNC are those with risk factors for re-intubation, as identified from previous studies, such as age $\geq 65$ years old, moderate to severe chronic obstructive pulmonary disease (COPD), multiple comorbidities, body mass index (BMI) $\geq 30$ (calculated as weight in kilograms divided by height in metres squared), heart failure and pneumonia as the primary indication for MV, higher severity of illness at ICU admission, inability to deal with respiratory secretions, and $\mathrm{MV} \geq 7$ days. ${ }^{18-23}$ However, despite use of HFNC in these patients, re-intubation rates still reach $20 \% .^{7-11}$ It is prudent to identify patient characteristics that can predict re-intubation when HFNC is used to facilitate extubation in these patients. To date, only a few observational studies have attempted to address this question, and report inconsistent results. ${ }^{24,25}$ In addition, while re-intubation in the non-HFNC settings has been associated with poorer outcomes, ${ }^{4-6}$ evidence suggestive of poorer outcomes is limited among patients with post-extubation HFNC failure. ${ }^{26} \mathrm{We}$ therefore aimed to identify independent predictors and outcomes of extubation failure in patients who failed post-extubation HFNC.

\section{METHODS}

\section{Study design and patient population}

A multicentre observational study was conducted in 9 adult ICUs across 5 public hospitals in Singapore from 1 January 2015 to 30 September 2017. Patients were included if they were older than 18 years and received HFNC immediately after extubation. Extubation required passing a spontaneous breathing trial, which involved pressure support ventilation $\left(\leq 10 \mathrm{~cm} \mathrm{H}_{2} \mathrm{O}\right)$ with positive end-expiratory pressure (PEEP) $\leq 8 \mathrm{~cm}$ $\mathrm{H}_{2} \mathrm{O}$ and inspired oxygen fraction $\left(\mathrm{FiO}_{2}\right) \leq 40 \%$. Patients with concomitant hypercapnia $\left(\mathrm{PaCO}_{2} \geq\right.$ $45 \mathrm{mmHg}$ ) in the pre-extubation arterial blood gas analysis were also included. Patients were excluded if they had do-not-intubate or do-not-resuscitate orders. Patients were followed up till death or hospital discharge. The National Healthcare Group Domain-Specific Review Board approved the study with a waiver of informed consent due to the noninterventional study design (DSRB 2017/00900).

\section{Clinical management and definition of failed HFNC}

HFNC was provided with one of the following devices: Optiflow, Bio-med or Airvo 2 (all from Fisher \& Paykel Healthcare, Auckland, New Zealand). HFNC was initiated at a minimum flow of $30 \mathrm{~L} / \mathrm{min}(30-60 \mathrm{~L} /$ min), titrating $\mathrm{FiO}_{2}$ to achieve an oxygen saturation of $\geq 92 \%$. Practice patterns were quite similar across various ICUs involved as discussed among the co-authors. Post-extubation use of HFNC as well as the need for re-intubation was decided by the treating clinicians based on their clinical judgement as deemed appropriate. Failed HFNC was defined as re-intubation 
within the first 7 days following extubation. ${ }^{3,27,28}$ Study protocol was to exclude patients who would have transitioned from HFNC to non-invasive ventilation.

\section{Data collection}

We collected data for patients' demographic characteristics, comorbidities, conventional risk factors for re-intubation as per non-HFNC studies, which included Acute Physiology and Chronic Health Evaluation (APACHE) II score, BMI, primary indication, pre-extubation duration of ventilation, inability to deal with respiratory secretions (defined as inadequate cough reflex or suctioning $>2$ times within 8 hours before extubation, as per the clinical notes) and fluid balance in 24 hours prior to extubation. ${ }^{18-23}$ Comorbidities included diabetes, hypertension, ischaemic heart disease, liver cirrhosis, stroke (ischaemic or haemorrhagic), asthma, COPD, other respiratory diseases, (bronchiectasis, interstitial lung disease), chronic kidney disease and immunosuppression.

The following clinical parameters were collected for the time period immediately prior to extubation: $\mathrm{pH}$, partial pressure of carbon dioxide $\left(\mathrm{PaCO}_{2}\right.$ in $\left.\mathrm{mmHg}\right)$, $\mathrm{PaO}_{2} / \mathrm{FiO}_{2}(\mathrm{P} / \mathrm{F})$ ratio and $\mathrm{SpO}_{2} / \mathrm{FiO}_{2}(\mathrm{~S} / \mathrm{F})$ ratio. Finally, outcome data of LOS (ICU and hospital) and mortality (ICU and hospital) were collected.

\section{Statistical analysis}

Our sample size calculation is based on the estimated re-intubation rate of $20 \%$. We hypothesised that there may be 3 predictors of post-extubation HFNC failure. Since about 10 events were required for each predictor, we calculated a sample size required of 150 or more. Categorical variables were reported as proportions and were compared using the chi-square test. Normallydistributed continuous variables were reported as means (standard deviation [SD]) and were compared using the Student t-test and Analysis of Variance. Non-parametric data were reported as medians (interquartile range [IQR]) and compared using the Wilcoxon rank-sum test. To determine factors independently associated with failed HFNC, variables with $P<0.2$ on univariate analysis were entered into a generalised additive logistic regression model. Continuous predictors were modelled using penalised regression splines to account for potential nonlinearity. All tests were two-sided and statistical significance was set at $P<0.05$.

\section{RESULTS}

Two hundred and forty-four patients (mean age $63.92 \pm 15.51$ years, $65.2 \%$ male, APACHE II score on ICU admission 23.55 \pm 7.35 ) were included. The reasons for initial intubation were: 97 (39.8\%) post-surgical patients; $86(35.2 \%)$ had respiratory distress such as pneumonia, acute respiratory distress syndrome and interstitial lung diseases; $32(13 \%)$ unable to protect their airway due to excessive secretion; 18 (7.4\%) intubated due to sudden drop in level of consciousness and remaining 11 (4.5\%) during resuscitation. Median duration of MV was 4.0 (IQR 2.0-6.0) days. Fortyone $(16.8 \%)$ patients needed re-intubation within the first 7 days following extubation (failed HFNC), 16 (39\%) for hypoxia, and remaining 25 patients (61\%) for non-hypoxia reasons. Of the 41 patients who failed HFNC, 27 (65.9\%) were re-intubated within 24 hours and $36(87.8 \%)$ were re-intubated within 72 hours. Among the latter 36 patients, $15(41.7 \%)$ were re-intubated because of hypoxia, 13 (36.1\%) developed respiratory acidosis, $10(27.8 \%)$ were unable to protect their airway due to excessive secretions, and 8 (22.2\%) developed increased work of breathing post-extubation (some patients had more than one indication for re-intubation). Of the remaining 5 patients requiring re-intubation after 72 hours (4 were re-intubated between 72 and 96 hours, and 1 at 120 hours), one each was for hypoxia, depressed level of consciousness and cardiorespiratory arrest, while 2 needed to undergo emergency surgery.

Patients who failed HFNC were similar to those who were successfully extubated with regards to baseline demographics, admission source, distribution of medical versus surgical cases, comorbid conditions, and arterial blood gas parameters prior to extubation (Tables 1 and 2). One hundred and ninety-two (79\%) patients had one or more conventional risk factors for re-intubation and had a $17.7 \%$ re-intubation rate, compared to $13.5 \%$ among patients with no conventional risk factors $(P=0.528)$.

The following factors had a $P$ value $<0.2$ on univariate analysis: age, stroke and chronic kidney disease as a comorbidity. Age was found to be non-linearly and non-significantly related to the risk of failed HFNC (Fig. 1). Generalised additive logistic regression for HFNC failure, using age (as spline term), stroke and chronic kidney disease as independent variables, identified stroke as the only independent predictor (odds ratio 2.48, 95\% confidence interval 1.83-3.37; $P=0.042$ ) (Table 3).

HFNC therapy duration was shorter among patients with failed HFNC compared to successful HFNC (median [interquartile range] $21.50(7.0-35.0)$ hours versus 41.0 (21.0-67.0) hours, respectively; $P=0.001)$. Failed HFNC was associated with increased ICU LOS, ICU mortality and hospital mortality (Table 4). 


\begin{tabular}{|c|c|c|c|c|}
\hline & $\begin{array}{l}\text { All Patients } \\
\qquad \begin{array}{l}\text { (N=244) } \\
\text { No. }(\%)\end{array}\end{array}$ & $\begin{array}{c}\begin{array}{l}\text { Successful HFNC } \\
(\mathbf{n}=\mathbf{2 0 3}) \\
\text { No. }(\%)\end{array}\end{array}$ & $\begin{array}{c}\text { Failed HFNC } \\
(n=41) \\
\text { No. }(\%)\end{array}$ & $P$ value \\
\hline Age, years $($ mean $\pm S D)$ & $63.92 \pm 15.51$ & $64.77 \pm 15.63$ & $59.76 \pm 14.35$ & 0.059 \\
\hline Male & $159(65.2)$ & $130(64.0)$ & $29(70.7)$ & 0.412 \\
\hline Admission source - ED & $63(25.8)$ & $54(26.6)$ & $9(22.0)$ & 0.342 \\
\hline Admission source - GW & $100(41.0)$ & $79(38.9)$ & $21(51.2)$ & \\
\hline Admission source - OT & $81(33.2)$ & $70(34.5)$ & $11(26.8)$ & \\
\hline Medical patients & $124(50.8)$ & $103(50.7)$ & $21(51.2)$ & 0.669 \\
\hline Surgical patients & $120(49.1)$ & $100(49.3)$ & $20(49.8)$ & \\
\hline Smoker & $40(16.4)$ & $32(15.8)$ & $8(19.5)$ & 0.448 \\
\hline Diabetes & $77(31.6)$ & $65(32.0)$ & $12(29.3)$ & 0.730 \\
\hline Hypertension & $154(63.1)$ & $130(64.0)$ & $24(58.5)$ & 0.505 \\
\hline Ischaemic heart disease & $58(23.8)$ & $47(23.2)$ & $11(26.8)$ & 0.614 \\
\hline Liver cirrhosis & $7(2.9)$ & $7(3.4)$ & $0(0.0)$ & 0.228 \\
\hline Stroke & $40(16.4)$ & $30(14.8)$ & $10(24.4)$ & 0.129 \\
\hline Asthma & $19(7.8)$ & $14(6.9)$ & $5(12.2)$ & 0.248 \\
\hline COPD & $14(5.7)$ & $13(6.4)$ & $1(2.4)$ & 0.319 \\
\hline Pneumonia & $60(24.6)$ & $51(25.1)$ & $9(22.0)$ & 0.667 \\
\hline Other respiratory disease & $11(4.3)$ & $10(4.7)$ & $1(2.4)$ & 0.497 \\
\hline Immunosuppression & $47(19.3)$ & $38(18.7)$ & $9(22.0)$ & 0.632 \\
\hline Mean APACHE II (mean \pm SD) & $23.55 \pm 7.35$ & $23.34 \pm 7.29$ & $24.64 \pm 7.65$ & 0.293 \\
\hline Vasopressor & $114(46.7)$ & $95(46.8)$ & $19(46.3)$ & 0.957 \\
\hline $\mathrm{BMI}(\mathrm{mean} \pm \mathrm{SD})$ & $24.13 \pm 5.55$ & $23.95 \pm 5.19$ & $25.03 \pm 7.04$ & 0.259 \\
\hline Inability to deal with respiratory secretions & $32(13.1)$ & $27(13.3)$ & $5(12.2)$ & 0.848 \\
\hline Fluid balance in 24 hours prior to extubation $(\mathrm{mL})($ mean $\pm S D)$ & $333.5(-61.3-882.5)$ & $303.0(-44.0-881.0)$ & $354.0(-241.5-1062.5)$ & 0.777 \\
\hline Duration of MV prior to extubation (days) median (IQR) & $4.0(2.0-6.0)$ & $4.0(2.0-6.0)$ & $4.0(2.8-7.3)$ & 0.244 \\
\hline Duration of MV prior to extubation $\geq 7$ days & $59(24.2)$ & $48(23.6)$ & $11(26.8)$ & 0.664 \\
\hline$\geq 1$ Risk factors for re-intubation & $192(78.7)$ & $158(77.8)$ & $34(82.9)$ & 0.467 \\
\hline
\end{tabular}

APACHE: Acute Physiology and Chronic Health Evaluation; BMI: body mass index; COPD: chronic obstructive pulmonary disease; ED: emergency department; GW: general ward; HFNC: high-flow nasal cannula; IQR: interquartile range; MV: mechanical ventilation; OT: operating theatre; SD: standard deviation

\section{DISCUSSION}

To our knowledge, ours is one of the largest studies worldwide to identify independent predictors for re-intubation and to describe outcomes in patients who failed post-extubation HFNC. Among patients who were put on HFNC post-extubation, our study demonstrated that stroke as a comorbidity was an independent risk factor for re-intubation. Failed HFNC was associated with increased ICU LOS, ICU mortality and hospital mortality.

Patients in our study had a HFNC failure rate of $16.8 \%$; the rate of re-intubation in previous studies has been shown to be $4.9 \%$ in the low-risk patients, and up to $22.8 \%$ in the high-risk patients receiving post- 
Table 2. Arterial blood gas measurements prior to extubation

\begin{tabular}{|c|c|c|c|c|}
\hline Parameter & $\begin{array}{l}\text { All Patients } \\
\qquad \begin{array}{c}(\mathbf{N}=\mathbf{2 4 4}) \\
\text { mean } \pm \text { SD }\end{array}\end{array}$ & $\begin{array}{c}\text { Successful HFNC } \\
(\mathbf{n}=\mathbf{2 0 3}) \\
\text { mean } \pm \text { SD }\end{array}$ & $\begin{array}{c}\text { Failed HFNC } \\
\quad(\mathbf{n}=\mathbf{4 1}) \\
\text { mean } \pm \text { SD }\end{array}$ & $P$ value \\
\hline $\mathrm{pH}$ & $7.42 \pm 0.056$ & $7.42 \pm 0.058$ & $7.41 \pm 0.045$ & 0.322 \\
\hline $\mathrm{PaCO}_{2}(\mathrm{mmHg})$ & $39.42 \pm 6.54$ & $39.36 \pm 6.30$ & $39.76 \pm 7.70$ & 0.720 \\
\hline $\mathrm{PaCO}_{2} \geq 45 \mathrm{mmHg}, \mathrm{n}(\%)$ & $44(18.0)$ & $36(17.7)$ & $8(19.5)$ & 0.787 \\
\hline $\mathrm{P} / \mathrm{F}$ ratio & $312.54 \pm 93.45$ & $314.66 \pm 93.53$ & $302.06 \pm 93.50$ & 0.432 \\
\hline $\mathrm{P} / \mathrm{F}$ ratio $\leq 200, \mathrm{n}(\%)$ & $34(13.9)$ & $29(14.3)$ & $5(12.2)$ & 0.724 \\
\hline $\mathrm{S} / \mathrm{F}$ ratio & $304.80 \pm 55.01$ & $306.21 \pm 55.09$ & $297.83 \pm 54.75$ & 0.375 \\
\hline
\end{tabular}

$\mathrm{PaCO}_{2}$ : partial pressure of arterial carbon dioxide; $\mathrm{P} / \mathrm{F}$ ratio: $\mathrm{PaO}_{2} / \mathrm{FiO}_{2} ; \mathrm{S} / \mathrm{F}$ ratio: $\mathrm{SpO}_{2} / \mathrm{FiO}_{2} ; \mathrm{PaO}_{2}$ : partial pressure of arterial oxygen; FiO : fraction of inspired oxygen; $\mathrm{SpO}_{2}$ : oxygen saturation on pulse oximeter; $\mathrm{SD}$ : standard deviation

Table 3. Generalised additive logistic regression model for failed HFNC

\begin{tabular}{lcc}
\hline Dependent variables & Odds ratio (95\% CI) & $\boldsymbol{P}$ value \\
\hline Age (as spline, see Fig. 1) & NA & 0.052 \\
\hline Stroke & $2.48(1.83-3.37)$ & $0.042^{\mathrm{a}}$ \\
Chronic kidney disease & $0.42(0.12-1.47)$ & 0.183 \\
\hline${ }^{a} P$ value $<0.05$ & & \\
CI: confidence interval; NA: not applicable & &
\end{tabular}

extubation HFNC therapy., ${ }^{7,-11}$ Majority of the patients in our study had one or more risk factors and therefore our failure rates are consistent with studies of highrisk patients.

Previous studies demonstrated that $20-40 \%$ of neurological patients required re-intubation following planned extubation. ${ }^{29,30}$ This high re-intubation rate could be attributed to ventilatory failure from impaired cough, inability to maintain a patent airway, and defective central respiratory control. HFNC per se does not mitigate these risk factors and may explain why stroke remains an independent predictor of failed HFNC post-extubation. Additionally, previous nonHFNC studies have demonstrated poor cough, copious secretions, inability to follow complex commands and ICU-acquired weakness to be associated with high risk of extubation failure. ${ }^{22,23,27}$ For such patients, other strategies such as non-invasive ventilation or early tracheostomy may be used to avoid extubation failure.

Our results differ from two recent smaller singlecentre retrospective studies of patients extubated to HFNC (84 and 165 patients, respectively). ${ }^{24,25}$ These studies identified longer hospital LOS and duration of MV prior to extubation, respectively as variables associated with re-intubation. Different patient case-mix (e.g. older age in first study compared to our study) and

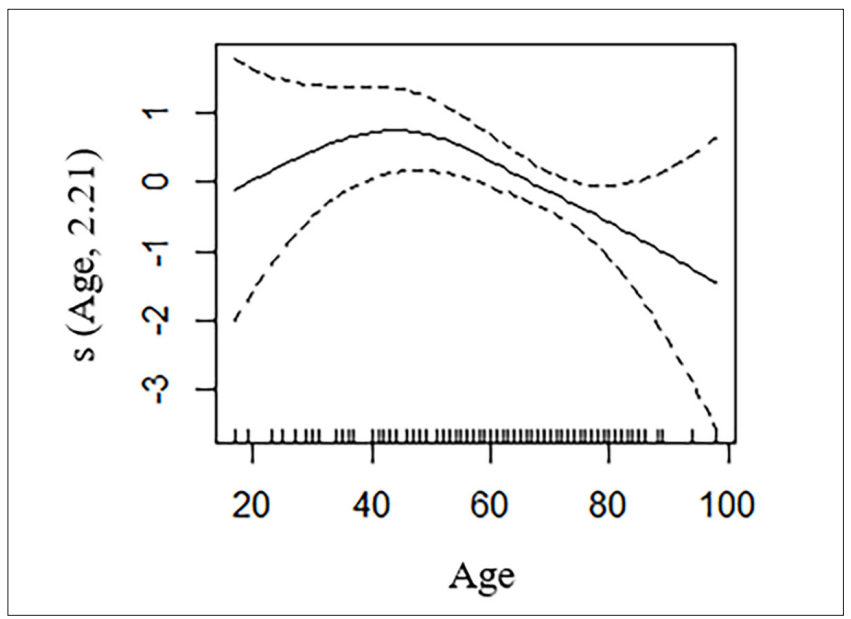

Fig. 1. Spline of age versus failed high-flow nasal cannula.

different protocols for HFNC usage (e.g. a fixed 24-hour HFNC protocol in the second study versus prolonged application of HFNC) may explain why results from prior studies differed from ours.

Non-HFNC studies of extubation failure have identified many other risk factors to be associated with re-intubation, namely, severity of illness at admission and hypoxia at time of extubation. ${ }^{20,21}$ Interestingly, post-extubation HFNC usage studies including our 
Table 4. Clinical outcomes

\begin{tabular}{|c|c|c|c|c|}
\hline Parameter & $\begin{array}{l}\text { All Patients } \\
(\mathbf{N}=\mathbf{2 4 4}) \\
\text { median (IQR) }\end{array}$ & $\begin{array}{c}\text { Successful HFNC } \\
(\mathbf{n}=\mathbf{2 0 3}) \\
\text { median (IQR) }\end{array}$ & $\begin{array}{c}\text { Failed HFNC } \\
(\mathbf{n}=\mathbf{4 1}) \\
\text { median (IQR) }\end{array}$ & $P$ value \\
\hline HFNC duration (hours) & $31.0(20.0-65.0)$ & $41.0(21.0-67.0)$ & $21.50(7.0-35.0)$ & $<0.001^{\mathrm{a}}$ \\
\hline ICU LOS (days) & $7.0(5.0-13.0)$ & $7.0(4.0-11.0)$ & $14.0(9.0-20.5)$ & $<0.001^{\mathrm{a}}$ \\
\hline Hospital LOS (days) & $32.0(18.0-53.0)$ & $31.0(18.0-51.0)$ & $44.0(21.5-58.5)$ & 0.229 \\
\hline ICU Mortality, n (\%) & $10(4.1)$ & $4(2.0)$ & $6(14.6)$ & $<0.001^{\mathrm{a}}$ \\
\hline Hospital Mortality, n (\%) & $37(15.2)$ & $25(12.3)$ & $12(29.3)$ & $0.006^{\mathrm{a}}$ \\
\hline
\end{tabular}

study have not demonstrated these risk factors to be predictive of failed HFNC..$^{10,24,25}$ On the other hand, post-extubation HFNC has neither been shown to reduce the risk of re-intubation consistently across various studies; despite decreasing the incidence of post-extubation respiratory failure..$^{29,31}$ This may highlight the need to further study the role of postextubation HFNC in larger studies to identify which patients are unlikely to benefit.

Patients in our study represented a high-risk group with high APACHE II score on admission and 79\% patients had at least one conventional risk factor for re-intubation. The re-intubation rate in the patients with no conventional risk factors was statistically similar to ones with conventional risk factors. This finding suggests that all the patients included in our study were at high-risk of re-intubation even without conventional risk factors. As expected, our study showed poorer outcomes among failed HFNC patients compared to the patients who were successfully extubated. Similar results were observed in a prospective observational study of 46 patients (half of whom were immunocompromised) where post-extubation HFNC failure was associated with high ICU and hospital mortality ( $50 \%$ and $62.5 \%$, respectively). ${ }^{26}$

A strength of our study was the inclusion of patients with mixed aetiologies for MV, derived from multiple ICUs. We also used a longer follow-up of 7 days to define failed HFNC as has been suggested in previous studies, $3,27,28$ which meant that both early and delayed re-intubations could be counted as failed HFNC events.

However, several limitations exist. Firstly, the decision for initial intubation, extubation, initiation of HFNC as well as re-intubation was not protocolised, although practice patterns were quite similar across various ICUs involved. It is unlikely that these practices in Singapore ICUs were different from other countries based on literature suggesting similar extubation failure rates in high-risk patients. ${ }^{9-11}$ Additionally, recent reviews of post-extubation HFNC use have identified the limitations of lack of data and significant heterogeneity among the published studies to be able to guide clinical practice in this setting. ${ }^{31,32}$ Generally, extubation required passing a spontaneous breathing trial, which involved pressure support ventilation $\left(\leq 10 \mathrm{~cm} \mathrm{H}_{2} \mathrm{O}\right)$ with $P E E P \leq 8 \mathrm{~cm} \mathrm{H}_{2} \mathrm{O}$ and inspired oxygen fraction $\left(\mathrm{FiO}_{2}\right) \leq 40 \%$. HFNC was initiated at a minimum flow of $30 \mathrm{~L} / \mathrm{min}(30-60 \mathrm{~L} / \mathrm{min})$ titrating $\mathrm{FiO}_{2}$ to achieve an oxygen saturation of $\geq 92 \%$. Secondly, we did not collect physiological details (hypoxia, hypercarbia or work of breathing) at the initial intubation, neither the details of the manipulations in the gas flows during HFNC period to facilitate HFNC success. Nonetheless, our re-intubation rate was similar to previous studies. ${ }^{9-11}$ Thirdly, clinical parameters at 12 and 24 hours postextubation were not evaluated as we wanted to focus on early prediction of HFNC failure prior to extubation. Fourthly, HFNC failure could be due to inadequacy of HFNC or failed extubation regardless of HFNC usage. However, our study was not designed to answer this question. Finally, although we included all possible variables that could be related to failed HFNC, other yet unknown risk factors could still exist.

Post-extubation HFNC failure, especially in patients with stroke as a comorbidity, remains a clinical challenge and predicts poorer clinical outcomes. Our observational study highlights the need for future prospective trials to better identify patients at high risk of post-extubation HFNC failure.

\section{REFERENCES}

1. Esteban A, Anzueto A, Frutos F, et al. Characteristics and outcomes in adult patients receiving mechanical ventilation: A 28-day international study. JAMA 2002;287:345-55.

2. Esteban A, Frutos-Vivar F, Muriel A, et al. Evolution of mortality over time in patients receiving mechanical ventilation. Am J Respir Crit Care Med 2013;188:220-30. 
3. Thille AW, Boissier F, Ben Ghezala H, et al. Risk factors for and prediction by caregivers of extubation failure in ICU patients: A prospective study. Crit Care Med 2015;43:613-20.

4. Thille AW, Harrois A, Schortgen F, et al. Outcomes of extubation failure in medical intensive care unit patients. Crit Care Med 2011;39:2612-8

5. Gao F, Yang LH, He HR, et al. The effect of reintubation on ventilator-associated pneumonia and mortality among mechanically ventilated patients with intubation: a systematic review and metaanalysis. Heart Lung 2016;45:363-71.

6. Frutos-Vivar F, Esteban A, Apezteguia C, et al. Outcome of reintubated patients after scheduled extubation. J Crit Care 2011; 26:502-9.

7. Hernandez G, Vaquero C, Gonzalez P, et al. Effect of postextubation high-flow nasal cannula vs conventional oxygen therapy on reintubation in low-risk patients: a randomized clinical trial. JAMA 2016;315:1354-61.

8. Maggiore SM, Idone FA, Festa R, et al. Nasal high-flow versus venturi mask oxygen therapy after extubation: effects on oxygenation, comfort, and clinical outcome. Am J Respir Crit Care Med 2014;190:282-8.

9. Hernández G, Vaquero C, Colinas L, et al. Effect of postextubation high-flow nasal cannula vs noninvasive ventilation on reintubation and postextubation respiratory failure in high-risk patients: a randomized clinical trial. JAMA 2016;316:1565-74.

10. Fernandez R, Subira C, Frutos-Vivar F, et al. High-flow nasal cannula to prevent post-extubation respiratory failure in high-risk nonhypercapnic patients: a randomized multicenter trial. Ann Intensive Care 2017;7:47.

11. Corley A, Bull T, Spooner AJ, et al. Direct extubation onto high-flow nasal cannulae post-cardiac surgery versus standard treatment in patients with a $\mathrm{BMI} \geq 30$ : a randomised controlled trial. Intensive Care Med 2015;41:887-94

12. Corley A, Caruana LR, Barnett AG, et al. Oxygen delivery through high-flow nasal cannulae increase end-expiratory lung volume and reduce respiratory rate in post-cardiac surgical patients. $\mathrm{Br} \mathrm{J}$ Anaesth 2011;107:998-1004.

13. Parke R, McGuinness S, Eccleston M. Nasal high-flow therapy delivers low level positive airway pressure. Br J Anaesth 2009; 103:886-90

14. Mündel T, Feng S, Tatkov S, et al. Mechanisms of nasal high flow on ventilation during wakefulness and sleep. J Appl Physiol (1985) 2013;114:1058-65.

15. Chanques G, Riboulet F, Molinari N. Comparison of three high flow oxygen therapy delivery devices: a clinical physiological cross-over study. Minerva Anestesiol 2013;79:1344-55.

16. Williams R, Rankin N, Smith T, et al. Relationship between the humidity and temperature of inspired gas and the function of the airway mucosa. Crit Care Med 1996;24:1920-9.
17. Moller W, Feng S, Domanski U, et al. Nasal high flow reduces dead space. J Appl Physiol (1985) 2017;122:191-7.

18. Ferrer M, Valencia M, Nicolas J, et al. Early noninvasive ventilation averts extubation failure in patients at risk - a randomized trial. Am J Respir Crit Care Med 2006;173:164-70.

19. Nava S, Gregoretti C, Fanfulla F, et al. Noninvasive ventilation to prevent respiratory failure after extubation in high-risk patients. Crit Care Med 2005;33:2465-70

20. Meade M, Guyatt G, Cook D, et al. Predicting success in weaning from mechanical ventilation. Chest 2001;120(Suppl 6):400-24.

21. Namen A, Ely E, Tatter S, et al. Predictors of successful extubation in neurosurgical patients. Am J Respir Crit Care Med 2001; 163:658-64

22. Salam A, Tilluckdharry L, Amoateng-Adjepong Y, et al. Neurologic status, cough, secretions and extubation outcomes. Intensive Care Med 2004;30:1334-9.

23. Mokhlesi B, Tulaimat A, Gluckman TJ, et al. Predicting extubation failure after successful completion of a spontaneous breathing trial. Respir Care 2007;52:1710-7.

24. Ezcurra P, Venuti MS, Gogniat E, et al. Prognostic factors for extubation failure in high risk patients using high-flow nasal cannula. Eur Respir J 2019;54(Suppl 63):PA4022.

25. Lee M, Kim JH, Jeong IB, et al. Protecting postextubation respiratory failure and reintubation by high-flow nasal cannula compared to low-flow oxygen system: single center retrospective study and literature review. Acute Crit Care 2019;34:60-70.

26. Goh KJ, Chai HZ, Ong TH, et al. Early prediction of high flow nasal cannula therapy outcomes using a modified ROX index incorporating heart rate. J Intensive Care 2020;8:41.

27. Thille AW, Boissier F, Muller M, et al. Role of ICU-acquired weakness on extubation outcome among patients at high risk of reintubation. Crit Care 2020;24:86.

28. Thille AW, Muller G, Gacouin A, et al. Effect of postextubation high-flow nasal oxygen with noninvasive ventilation vs high-flow nasal oxygen alone on reintubation among patients at high risk of extubation failure: a randomized clinical trial. JAMA 2019; 322:1465-75.

29. Wang S, Zhang L, Huang K, et al. Predictors of extubation failure in neurocritical patients identified by a systematic review and metaanalysis. PLoS One 2014;9:e112198.

30. Wendell LC, Raser J, Kasner S, et al. Predictors of extubation success in patients with middle cerebral artery acute ischemic stroke. Stroke Res Treat 2011;2011:248789.

31. Zhu Y, Yin H, Zhang R, et al. High-flow nasal cannula oxygen therapy versus conventional oxygen therapy in patients after planned extubation: a systematic review and meta-analysis. Crit Care 2019; 23:180.

32. Rochwerg B, Einav S, Chaudhuri D, et al. The role for high flow nasal cannula as a respiratory support strategy in adults: a clinical practice guideline. Intensive Care Med 2020;46:2226-37. 